\title{
Os rumos da Atenção Primária e da Estratégia Saúde da Família no Brasil
}

\author{
The way forward of Primary Care and Family Health Program in Brazil \\ Las rutas de la Atención Primaria y Salud Familiar en Brasil \\ Gustavo Diniz Ferreira Gusso ${ }^{1}$
}

A Sociedade Brasileira de Medicina de Família e Comunidade (SBMFC) é uma entidade científica e, por isso, o foco de atuação não é sindical. As defesas das formas de remuneração e plano de carreira devem ser feitas com base em estudos e experiências nacionais e internacionais. O mesmo ocorre quando algumas vezes é necessário criticar gestões e gestores. Neste sentido, é impossível não tocar nos rumos que a política de atenção básica vêm tomando.

Inicialmente, é preciso apontar a frustração que abateu os Médicos de Família e Comunidade e os profissionais da Atenção Primária à Saúde (APS), em geral, quando nos primeiros dias da nova gestão do Ministério da Saúde foi anunciada a suspensão das Portarias 3.839, de 7 de dezembro de 2010, e 4.299, de 30 de dezembro de 2010, as quais pagariam mais aos profissionais mais qualificados. Era uma luta de quatro anos. Assim como os profissionais da APS, uma das principais características que os gestores precisam ter é compreender a história de determinada área que está sob sua coordenação, e tentar fazer com que os processos positivos continuem. Muito frequentemente é necessária, de tempos em tempos, uma reformulação que deve levar em conta essa história, fortalecendo os pontos favoráveis e corrigindo as deficiências. Isto foi feito com maestria em 1993 na concepção do Programa Saúde da Família (PSF); de 1996 a 1998, na passagem para estratégia nacional e na criação dos Pisos de Atenção Básica (PABs) fixo e variável e, em 2006, quando foi editada a Política Nacional de Atenção Básica (PNAB) vigente. Foram ações que tiveram uma continuidade, embora fossem exercidas por diferentes gestores. Mas eles tiveram a sensibilidade de empurrar 'o paciente' para frente, muitas vezes lutando contra tempos políticos e marqueteiros que querem sempre criar uma nova marca.

A Estratégia Saúde da Família (ESF) é o programa de qualificação da APS de maior sucesso da história do Brasil ${ }^{1-6}$.

Não pode-se dizer que somente agora será introduzido um programa de qualificação da Atenção Básica, pois este existe há 15 anos com muitos estudos mostrando sua efetividade. Não pode-se alegar também que essa política é rígida, pois o PAB fixo é desvinculado de qualquer modelo de organização da rede de atenção e, infelizmente, permite que o gestor local se baseie na lógica de mercado, a qual, na maioria das vezes, é utilizada por ele e sua família com especialistas focais na porta de entrada do sistema. Além disso, o PAB variável incentiva a qualificação por meio da formação de equipes focadas na verdadeira integrali-

Presidente da Sociedade Brasileira de Medicina de Família e Comunidade (SBMFC). Docente do Departamento de Clínica Médica da Faculdade de Medicina da Universidade de São Paulo (USP). gusso.gustavo@gmail.com 
dade e não na integralidade como era conhecida até recentemente, ou seja, uma amálgama de especialidades médicas que se dividia por faixa etária ou sexo, em que cada uma cuidava de um programa vertical ou de uma parte da demanda. Esta medicina fragmentada é um dos motivos do fracasso do sistema privado brasileiro, que faz da saúde um comércio e que muitas vezes os políticos utilizam de forma irresponsável, causando claramente danos aos seus próprios corpos e dando maus exemplos a toda população.

Embora a ESF tenha problemas, os principais não são especificamente dela. O PAB fixo deveria estar entre 39 e 44 reais e, atualmente, está a metade disso. As unidades de saúde não têm infraestrutura adequada e os profissionais não têm a oportunidade de capacitação mínima nem de desenvolvimento profissional continuado. Portanto, a criação de um suposto programa de qualificação com indicadores verticais não resolverá estas deficiências, que são conhecidas por todos os que trabalham na APS brasileira. Além disso, não é adequado investir um grande recurso na avaliação com metodologia questionável, já que as universidades brasileiras de maneira geral não estão preparadas nem para ensinar ou avaliar a APS, deixando de aplicar na melhoria do sistema em si.

Outro problema é que o termo flexibilização tem sido usado de maneiras muito distintas. A PNAB vigente cumpriu um papel bastante relevante no país ao conseguir impulsionar uma política que vinha sendo construída por outros governos. Mas tem um problema: a flexibilidade de modelos. O PAB fixo, que representa grande parte do financiamento, não é atrelado a nenhum modelo que garanta qualidade como é a ESF, que, na essência, nada mais é do que a garantia de uma equipe de generalistas na porta de entrada do sistema, exercendo o papel de filtro e evitando a fragmentação. Mesmo assim, por causa do sucesso e das evidências estudadas ao longo dos anos, conseguiu-se uma substituição grande e, atualmente, a maior parte da APS brasileira é feita por meio da ESF.

O Brasil é heterogêneo e deve haver flexibilidade nas formas de remuneração e na carga horária, mas a equipe deve sempre ter um generalista bem formado. É assim que ocorre com a população europeia, a qual é ainda mais heterogênea e exigente do que a brasileira. Este é um dos motivos pelos quais foi parafraseada a Organização Mundial da Saúde (OMS). Diz-se: "Medicina de Família e Comunidade - agora mais do que nunca". Um dos grandes legados de Barbara Starfield é justamente a demonstração de que países com um generalista bem formado na porta de entrada do sistema, exercendo o papel de filtro, consegue melhores resultados. Este é um ponto em que não se pode haver flexibilização, e inúmeras pesquisas demonstraram isto ${ }^{7-9}$. Este profissional não era valorizado antes da ESF. Em geral os profissionais escolhem fazer Medicina de Família e Comunidade (MFC) também por ser uma necessidade do país e não defendem que a porta de entrada do sistema seja feita por um generalista por questões corporativistas. É o inverso. Por que no Brasil há tanta dificuldade para se defender o generalista ou o médico de família e comunidade? Por que os gestores resistem tanto em regular o sistema? É necessário tentar responder a estas perguntas.

Um dos principais motivos se encontra nas classes média e política, que querem continuar utilizando o sistema de saúde como um Shopping Center, realizando o exame de Papanicolau com um ginecologista famoso e levando os filhos para fazerem puericultura com o Pediatra que solicita retornos mensais, mesmo quando não há nenhum motivo para isto, exceto o lucro. Há 30 anos no Brasil, muitos pesquisadores e gestores que se dedicam à APS não acreditam que o generalista bem formado inserido na equipe não é um modelo insuperável, apesar de toda experiência internacional e dos estudos. Atualmente não é diferente, ou seja, tem sido sugerido que os indicadores de qualidade (verticais), enfim, avaliarão qual modelo realmente funciona melhor.

A proposta da SBMFC é que os indicadores verticais devem ser complementares e secundários, ou seja, antes devem haver indicadores que meçam a existência de uma rede consistente de (APS). Não se pode exigir cobertura de mamografia e Papanicolau se não 
há uma rede estruturada. Será trágico continuar sem essa rede, ou seja, sem avaliar os riscos individuais e ter apenas a cobertura de alguns exames resolvida como se os dados fossem produzidos artificialmente às custas da saúde da população, que terá que buscar cada vez mais as urgências. Como sabe-se pelas experiências internacionais, os riscos populacionais e individuais devem ser abordados pela mesma equipe de generalistas e não em Unidades de Pronto-Atendimento (correspondentes às walk in clinics). A ideia das redes verticais (urgência, maternoinfantil ou cegonha) representa um enorme retrocesso, e a possibilidade de desarticulação das redes integradas (primárias, secundárias e terciárias) que foram construídas nos últimos anos e que precisam ser aprimoradas com financiamento adequado.

Desta forma, os indicadores devem ser focados neste momento em estrutura e processo de acordo com os atributos da APS, como ocorre com o Primary Care Assessment Tool ${ }^{10}$, ou seja, acesso, coordenação, integralidade, longitudinalidade, orientação familiar e comunitária, além de competência cultural. Não se pode exigir resultados sem estrutura e processo. Neste sentido,os principais indicadores seriam: infraestrutura da Unidade de Saúde; grau de afiliação da população (serviço considerado referência); equipes trabalhando com uma população inferior a 3.000 habitantes; profissionais que participam de um processo de educação permanente; profissionais com formação para atuar na APS, hierarquizando as diferentes modalidades com maior valorização, no caso do médico, da residência em MFC ou título de especialista em MFC; tempo dos profissionais na mesma equipe; rol de procedimentos disponibilizados pela equipe; tempo de demora para agendamento de uma consulta com o médico da equipe; e acesso a consultas do mesmo dia (acolhimento e demanda espontânea).

Quanto à carga horária, se, por um lado, precisa flexibilização, nenhuma ação vai ajudar se não houver a definitiva regulação da formação, em especial na medicina, com residência para todos em médio prazo e $40 \%$ das vagas para MFC, como ocorre em praticamente todos os países que têm um sistema público de saúde universal e equânime ${ }^{11}$. A simples redução da carga horária representará a desassistência imediata de milhões de pessoas. Mais uma vez, a palavra de ordem não é flexibilização, mas sim reforma ampla com regulação. É fundamental dizer o que pode e o que não pode. Quem for se dedicar a 20 ou 30 horas, não poderia trabalhar o restante no sistema privado, mas sim cuidar da sua vida pessoal, trabalhar na gestão, pesquisa ou ensino da APS ou realizar plantões na rede do Sistema Único de Saúde (SUS).

Outro item que merece destaque é a desejável escolha dos pacientes pela sua equipe. Embora a PNAB vigente não diga que é proibida tal flexibilização para usar o jargão neoliberal adotado de forma não-criteriosa pela atual direção do Departamento de Atenção Básica (DAB) do Ministério da Saúde, quem já tentou aplicar sabe das dificuldades. Mais uma vez é preciso uma intervenção nas bases do sistema com muito investimento, pois os obstáculos não são uma portaria, mas, dentre outros, a heterogeneidade dos profissionais, o sistema de remuneração que privilegia o salário fixo ao invés do pagamento por captação, o excesso de pessoas por equipe e mais uma vez a carência de profissionais formados especificamente para trabalhar na APS, um ambiente sabidamente com elevado grau de complexidade.

A ESF progrediu muito de 1994 até o presente momento, apesar de pesquisadores estagnados ainda interpretá-la como uma política parada no tempo. As acusações de rigidez, que já não fazem mais sentido, servem apenas para desviar o foco dos investimentos e reformas das bases, tanto na formação quanto na gestão que neste momento são fundamentais para o avanço. Além disso, elas ajudam a manter o conforto dos políticos com a classe média brasileira que deseja o SUS para intervenções de alta densidade tecnológica e o privado para acesso direto ao sistema secundário, ou seja, uma saúde comercial que agrava a lei dos cuidados inversos ${ }^{12}$. 
Por fim, é preciso manter o grau de internacionalização da APS. O Brasil atingiu um ponto em que serve de inspiração para muitos países, e é responsável por isso. Em todos os lugares há problemas, mas é preciso corrigi-los de maneira focada e sempre visando à integralidade. O professor Eugênio Villaça Mendes costuma dizer em suas palestras que a ESF é uma solução com problemas. Talvez seja a definição mais precisa. É imperativo resolver a obsessão que muitos ainda têm pela verticalização e por ações programáticas. São formas de trabalho superadas no mundo todo que prosperaram na extinta União Soviética e que paradoxalmente passaram a caminhar junto com as políticas neoliberais e mercadológicas. É fundamental uma modernização no Movimento da Reforma Sanitária brasileira, a qual agregue também quem está no dia-a-dia das equipes. Os profissionais que migram para a docência, a gestão e a pesquisa não devem abandonar completamente o vínculo com a assistência, pois podem perder a integralidade e o foco na pessoa.

Por isso também, um dos temas que deve ser mais discutido é o excesso de prevenção, em especial, secundária. Sabe-se que é difícil mudar paradigmas e entender que o foco na prevenção secundária é um equívoco que atrapalha a equipe toda e nos distancia dos pacientes. Além disso, uma indústria da prevenção (pornoprevenção ${ }^{13}$ ) está crescendo no mundo todo. Grandes hospitais de São Paulo criaram unidades enormes para checkups.

Enfim, o foco da APS não é a mamografia, o Papanicolau ou qualquer outro exame, mas sim o paciente e, para cada indivíduo, uma estratégia preventiva individualizada e com priorizações deve ser traçada com base nas melhores evidências científicas ${ }^{14}$. O Ministério da Saúde tem ainda que romper com uma estrutura bastante anacrônica bem antiga para poder parar de alimentar a verticalização que impõe o desvio dos recursos de quem mais precisa para as classes mais abastadas. Estas utilizam a prevenção, conceito também aplicado indiscriminadamente de forma excessiva como prática hedonista com a chancela do governo, da mídia, de parte dos pesquisadores e dos especialistas focais renomados, os quais têm sua experiência baseada em consultórios privados (e caros), cuja maior clientela são os pacientes inadequados por terem problemas inespecíficos e não da área para o qual foram treinados e que não passaram por um essencial filtro ${ }^{15}$ de um generalista bem formado.

É preciso, mais uma vez, usar de forma apropriada a medicina baseada em evidências. Pegando como exemplo o câncer de mama, o aumento de sua incidência é apenas um indício do envelhecimento da população e da melhoria econômica do país. Além disso, não há problema em morrer de câncer de mama aos 80 anos de idade. O que é preciso avaliar é se há suporte, se os idosos abastados morrem sem dor e assistidos em casa ou entubados em uma Unidade de Terapia Intensiva de um hospital publico ou privado às custas de uma parte da população que luta para sair da miséria. É fundamental impedir que profissionais de saúde utilizem as estatísticas, de forma distorcida, ou os casos excepcionais para assustar a população incentivando a medicina preventiva baseada no medo.

A SBMFC não tem nenhum vínculo com a indústria farmacêutica e nunca alguma ação foi subsidiada por ela. A entidade vive da contribuição dos sócios e de convênios com governos, especialmente com o DAB do Ministério da Saúde, mas nunca aceitou patrulha ideológica. Mesmo não tendo nenhum incentivo da indústria e apesar de ser uma entidade médica, que tem como uma das suas principais missões o fortalecimento do SUS, a SBMFC não é recordista em captação de recursos públicos - passa longe disto.

Embora o mundo seja repleto de incertezas - e é bom que seja assim -, o maior desejo é que os Médicos de Família e Comunidade e os profissionais da APS, que acreditam em um sistema de saúde não-comercial e regulado, possam continuar contribuindo para a construção do SUS, ou seja, que sejam valorizados pelos dirigentes e pelas políticas públicas e não sejam engolidos pelo mercado e pela política neoliberal. Esta está cada vez mais presente 
nesta área. Só o futuro dirá. É importante manter a crença de que o futuro do Brasil e do SUS não pertence apenas aos burocratas, mas também está nas mãos de quem se dedica a atender as pessoas sem distinção de sexo, idade ou órgão acometido.

\section{Referências}

1. Macinko J, Guanais FC, de Fátima M, de Souza M. Evaluation of the impact of the Family Health Program on infant mortality in Brazil, 1990-2002. J Epidemiol Community Health. 2006; 60: 13-9. http://dx.doi.org/10.1136/jech.2005.038323

2. Rasella D, Aquino R, Barreto ML. Reducing childhood mortality from diarrhea and lower respiratory tract infections in Brazil. Pediatrics. 2010; 126(3): e534-40. http://dx.doi.org/10.1542/peds.2009-3197

3. Macinko J, Dourado I, Aquino R, Bonolo Pde F, Lima-Costa MF, Medina MG, et al. Major expansion of primary care in Brazil linked to decline in unnecessary hospitalization. Health Aff. 2010; 29(12): 2149-60. http://dx.doi.org/10.1377/hlthaff.2010.0251

4. Paim J, Travassos C, Almeida C, Bahia L, Macinko J. The Brazilian health system: history, advances, and challenges. Lancet [periódico online]. 2011; 377(9779): 1778-97. Disponível em: http://www.thelancet.com/journals/lancet/article/PIIS0140-6736(11)60054-8/fulltext http://dx.doi.org/10.1016/S0140-6736(11)60054-8

5. Schmidt MI, Duncan BB, Silva GA, Menezes AM, Monteiro CA, Barreto SM, et al. Chronic non-communicable diseases in Brazil: burden and current challenges. Lancet [periódico online]. 2011; 377(9781): 1949-61. Disponível em: http://www.thelancet.com/journals/lancet/article/PIIS0140-6736\%2811\%2960135-9/fulltext http://dx.doi.org/10.1016/S0140-6736(11)60135-9

6. Victora CG, Aquino EML, Leal MC, Monteiro CA, Barros FC, Szwarcwald CL. Maternal and child health in Brazil: progress and challenges. Lancet [periódico online]. 2011; 377(9780): 1863-76. Disponível em: http://www.thelancet.com/journals/lancet/article/PIIS0140-6736\%2811\%2960138-4/fulltext http://dx.doi.org/10.1016/S0140-6736(11)60138-4

7. Starfield B. Atenção Primária. Equilíbrio entre necessidades de saúde, serviços e tecnologia. Brasília: UNESCO, Ministério da Saúde; 2002.

8. Starfield B. Is primary care essential? Lancet. 1994; 344(8930): 1129-33. http://dx.doi.org/10.1016/S0140-6736\%2894\%2990634-3

9. StarfieldB, ShiL.Policyrelevant determinantsofhealth:aninternational perspective. HealthPolicy. 2002;60(3):201-18. http://dx.doi.org/10.1016/S0168-8510(01)00208-1

10. Brasil. Ministério da Saúde. Secretaria de Atenção em Saúde. Departamento de Atenção Básica. Manual do Instrumento de Avaliação da Atenção Primária à Saúde: Primary Care Assessment Tool PCATool-Brasil. [Manual online] Brasília: Ministério da Saúde; 2010. Disponível em: http://189.28.128.100/dab/docs/publicacoes/geral/manual_instrumento_avaliacao.pdf

11. CARMS. Canadian Resident Matching Service. [página da Internet]. Acesso em 30 de Jun de 2011]. Disponível em: https://w1c.e-carms.ca/pdws2011R1-1/jsp/pd.do?p=p1\&m=1

12. Hart JT. The inverse care law. Lancet. 1971; 1(7696): 405-12. http://dx.doi.org/10.1016/S0140-6736(71)92410-X

13. Verdú V. Pornoprevención. El País. 2003; (9350): 29.

14. Rose G. Sick individuals and sick populations. Int J Epidemiol. 1985; 14: 32-8. http://dx.doi.org/10.1093/ije/14.1.32

15. Gérvas J, Pérez Fernández M. El fundamento científico de la función de filtro del médico general. Rev Bras Epidemiol. 2005; 8(2): 205-18. http://dx.doi.org/10.1590/S1415-790X2005000200013 